\title{
A N-D VIRTUAL NOTEBOOK ABOUT THE BASILICA OF S. AMBROGIO IN MILAN: INFORMATION MODELING FOR THE COMMUNICATION OF HISTORICAL PHASES SUBTRACTION PROCESS
}

\author{
C. Stanga ${ }^{a}$, C. Spinelli ${ }^{b}$, R. Brumana ${ }^{b}$, D. Oreni ${ }^{b}$, R. Valente ${ }^{b}$, F. Banfi ${ }^{b}$ \\ ${ }^{a}$ Graduate School in Architectural and Landscape Heritage, Department of Architecture and Urban Studies, \\ 20133 Milan, Italy - chiara.stanga@mail.polimi.it \\ ${ }^{\mathrm{b}}$ Department of Architecture, Built Environment and Construction Engineering, 20133 Milan, Italy - \\ chiara.spinelli@mail.polimi.it; (raffaella.brumana; daniela.oreni; riccardo.valente; fabrizio.banfi)@polimi.it
}

\section{Commission II}

KEY WORDS: Built Heritage, 3D Modelling, Laser Scanner, Photogrammetry, Disseminating Heritage Information

\begin{abstract}
:
This essay describes the combination of 3D solutions and software techniques with traditional studies and researches in order to achieve an integrated digital documentation between performed surveys, collected data, and historical research. The approach of this study is based on the comparison of survey data with historical research, and interpretations deduced from a data cross-check between the two mentioned sources. The case study is the Basilica of S. Ambrogio in Milan, one of the greatest monuments in the city, a pillar of the Christianity and of the History of Architecture. It is characterized by a complex stratification of phases of restoration and transformation. Rediscovering the great richness of the traditional architectural notebook, which collected surveys and data, this research aims to realize a virtual notebook, based on a 3D model that supports the dissemination of the collected information. It can potentially be understandable and accessible by anyone through the development of a mobile app. The 3D model was used to explore the different historical phases, starting from the recent layers to the oldest ones, through a virtual subtraction process, following the methods of Archaeology of Architecture. Its components can be imported into parametric software and recognized both in their morphological and typological aspects. It is based on the concept of LoD and ReverseLoD in order to fit the accuracy required by each step of the research.

\section{INTRODUCTION}

Founded in the late IV century by Archbishop Ambrogio, the Basilica of S. Ambrogio had a prominent role in the history of Milan and Christianity and still represents one of the greatest monuments in the city, visited by thousands of tourists every year. The first step was to have an overview of the transformation that occurred at the macro-scale, taking a hard

look at the Basilca's surroundings, trying to correlate the existing context reports with the historical cartography. This way it was possible to understand the interactions between the church and its environment, and comprehend the reasons of its location. The Basilica's context went through many changes over the years - starting from the recent transformation, the main ones are: the fall of the rectory after the bombing of the Second World War; the project of isolation of the Basilica from its surroundings in the first half of the XX century that changed the northern side of the church; Bramante's project of the
\end{abstract}
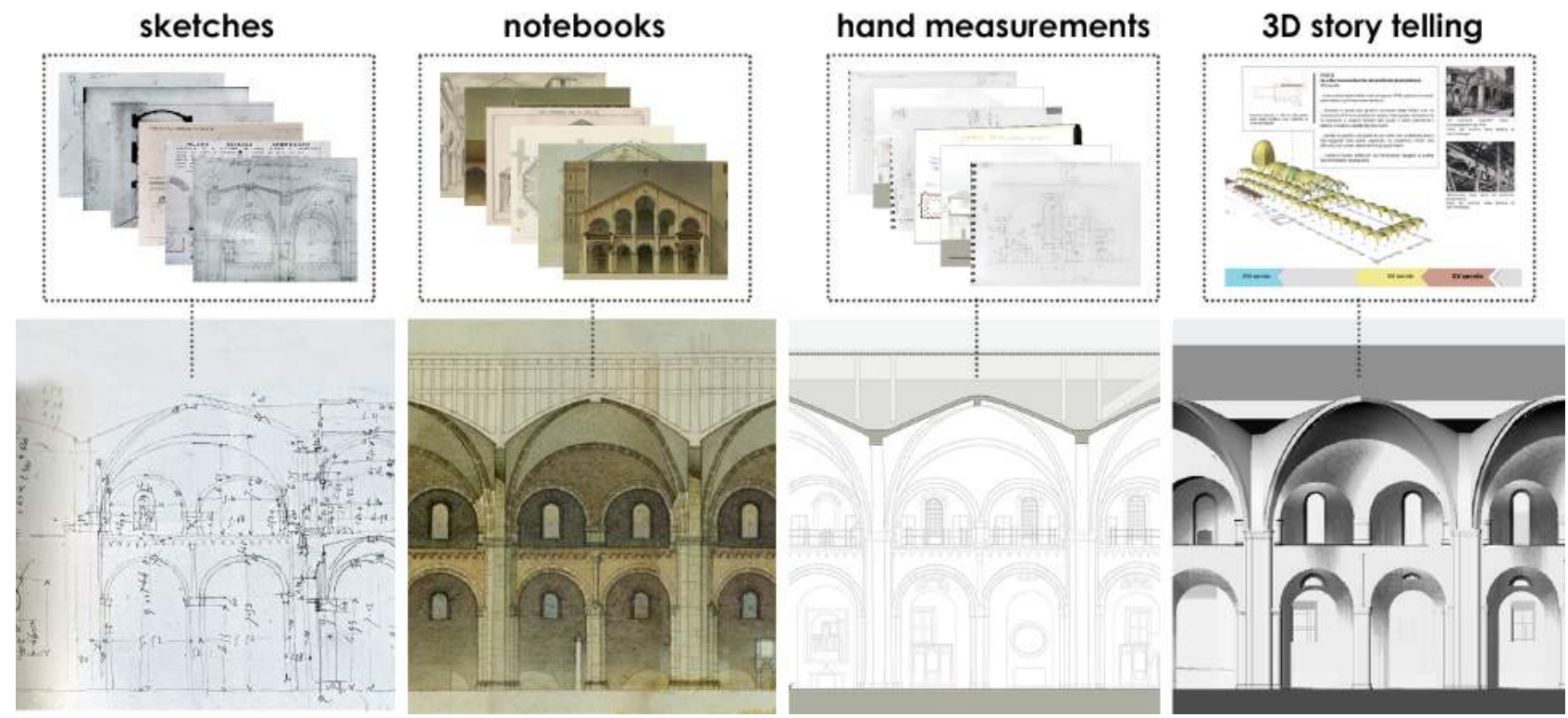

Figure 1. From traditional to virtual notebook 
rectory (northern aisle) and Cloisters (southern side). The correlation of this study with the analysis of the alignment of the Basilica's main structures (walls, apsis, chapels) reveals that there is no specific direction with a homogeneous design scheme but the church was built respecting the preexisting constructions. Going back to its origins, the Basilica was part of a wide project by Archbishop Ambrogio who wanted to establish four churches, located in specific significant sites in the city: S. Ambrogio (Basilica Martyrum), S. Nazaro (Basilica Apostolorum), S. Simpliciano (Basilica Virginum), S. Dionigi (Basilica Prophetarum) (Lusuardi Siena, 1997). In particular, the Basilica was built on a former funerary area and its construction strengthens an existing worship place (Sannazaro, 2009). Although considered as an unicum - one of the highest examples of the Romanesque architecture in Lombardy - the Basilica went through major changes over the centuries that deeply influence its constructive materials, arrangements and morphology. The main transformations regarded the restoration projects of the XX (before and after the damages occurred during the Second World War) and XIX centuries (led by Mons. F. M. Rossi, and the architects Landriani and De Dartein), the renovation of the dome and the four-sided portico in the Baroque, Bramante's rectory project in the Renaissance and the rifabbrica romanica (Romanesque reconstruction) in the Middle Ages.

\section{RESEARCH METHODOLOGY}

2.1 A Virtual Notebook for the communication of the historical phases subtraction process: story telling of the complexity for awareness rising among visitors and tourists

Regarded as one of the greatest examples of the Romanesque architecture in Lombardy, the church has been studied over the past years from various points of view and by several experts: its bibliography contains a great number of articles, books, guides, and notebooks. The latters have always been used by researchers as a tool for documenting buildings, collecting sketches, boards, personal interpretation, and data, for example: Fernand de Dartein's notebook helped understand the historical phases of the church's vaulted system, which had been altered through the years and in particular during the XIX century as de Dartein recorded. De Dartein (1838-1912) was an Alsatian architect who studied the Romanesque architecture in Lombardy and had the opportunity to see the Basilica during the XIX century restoration. Part of his notebook was recently published (Bella, 2013) and it is a great source of information thanks to the many sketches and drawings of the geometrical surveys of the church togheter with the data collected in the letters he wrote to architect Landriani. In this research the concept of the traditional notebook was used as a 'key-idea' and as a tool to organize, represent, and show the data collected during each step of the study. The idea is to collect survey and historical data, sketches, drawings, and photos in a virtual notebook, accessible by anyone at any given time. This virtual notebook is meant to summarize the whole work on the Basilica, depicting and presenting the virtual subtraction process of each historical phase as clearly as possible (Figure 1).

\subsection{Archaeology of Architecture}

The opportunity to study such a famous building represented a challenge and while the church has always been regarded as a whole unit, it has gone through major changes over time and it is still possible to find traces of these events on its structures. The integrated approach used for this study is based on the comparison of 'direct' and 'indirect' sources: the first one is the building itself, while the second are documents, chronicles, photos, and drawings about the church. They are an 'indirect' source because they are influenced by external factors, like the author and the period in which they were written or taken, while materials and constructive techniques are tangible and visible 'signs' - 'direct' sources that can be studied through different kinds of survey: from the geometrical ones to the material and stratigraphic analysis (Boato, 2008). Furthermore, although there are several drawings of the church until XX century, a detailed geometrical survey with laser scanning and photogrammetric techniques hasn't existed until this research. The correlation between survey data, historical research, and interpretations deduced from a data cross-check between the two mentioned sources, helped the correlation of the geometrical-dimensional data with the historical one. While doing so, it was possible to show aspects that hadn't been fully analyzed before. Furthermore, the study focuses not so much on providing answers to the many pending questions on the Basilica, but to open new horizons and perspectives of research (Figure 2). The idea was to study the complexity of the building from both the architectural and the archaeological points of view, adopting the appropriate instruments of archaeology for a 'direct' observation of the building (Boato, 2008). At the same time, archaeology was adopted in its 'subtraction excavation concept', exploring the Basilica through a virtual subtraction process - this way, the church itself becomes the main source on which the study is based, understanding its geometry, materials and construction techniques. That is why, instead of offering a conventional report on the monument, from its foundation to present day, the research used a virtual subtraction process to explore the different historical phases, starting from the recent 'signs' and going back to the older ones. Bibliography and focused archive research supported the analysis on the observations and data coming from the on-site visits of the building. Also, the 3D model was realized with the same purpose and made the application of this methodology possible, by reproducing the virtual subtraction process of the historical phases and of each element. It also supported the hypothesis formulated with the gathered data. The virtual subtraction process started with two important restoration project led by architect Ferdinando Reggiori, who studied the Basilica before and after the Second World War (1930-40; 1943-60). It then presented the 'interpretive' restorations of Monsignor Francesco Maria Rossi in the XIX century; it went

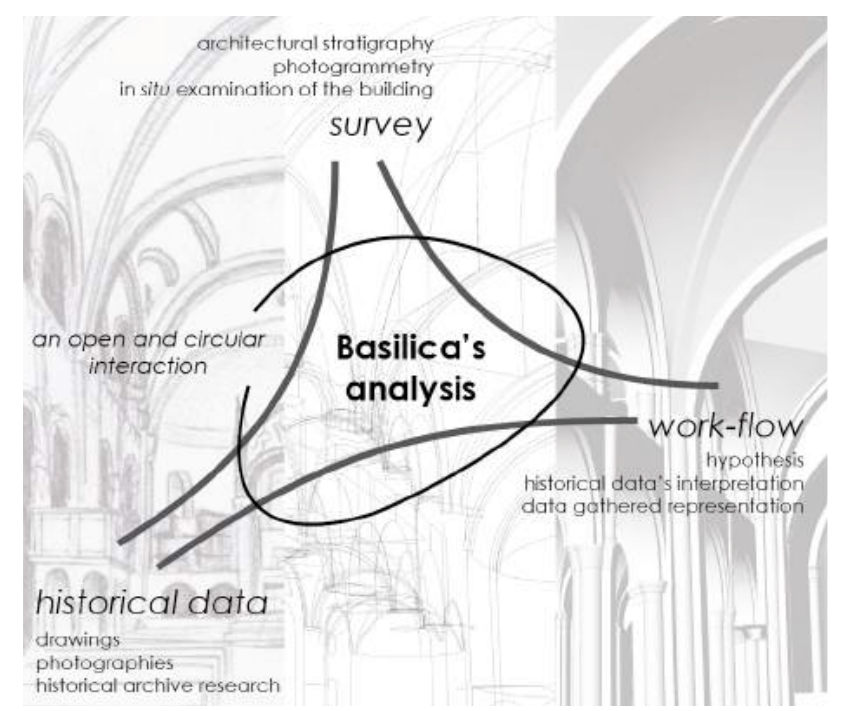

Figure 2. Circular interaction between the involved knowledges 
on to analyze the transformations occurred in the Baroque, and in the Renaissance - especially Bramante's work for the new rectory and the two cloisters of the Benedictine monastery (Università Cattolica del Sacro Cuore). The last two phases taken into consideration were the Middle Age and the late IV century A.D., when archbishop Ambrogio founded the Basilica (Gatti Perer, 1995). For each of these periods of time, a particular feature of the Basilica was analyzed, using 3D modeling (Rhinoceros) and photogrammetry (Agisoft PhotoScan), together with the laser scanner surveying that allowed the recreation of the complex structure of each element, which could then be imported into parametric software and recognized in both its morphological and typological aspects. Its characteristics change depending on the level of accuracy suitable for each examined feature (LoDs and ReversLoDs). An inverse timeline was created to make better understand the study: it represents the centuries from present days to the foundation of the Basilica, and assigns a color for each one in order to easily recognize them in each drawing. This essay describes two examples of this integrated approach applied to two complex structures: the vaulted system and the arc structures that lean against the perimetral wall of the church. By doing so, it is possible to see the different Level of Detail adopted.

\subsection{Through a H-BIM for the Basilica of S. Ambrogio}

The generation of the H-BIM of Basilica of Sant'Ambrogio has been mainly characterised by four phases, strategically correlated and integrated with each other. The ReverseLoD (Banfi, 2016) has favoured the creation of a historic BIM able to adapt to the different needs during its Life Cycle of Building (LCB), achieving a high level of detail (LoD) and avoiding the remodelling of geometric primitives for the generation of complex structural elements. The primary objective of the generative process was a proper management of high Level of Information (LOI) directly linked to the digital model starting from a significant amount of 3D survey data and historical document analysis (Fai et al., 2011). The first challenge was to bridge the gap between the BIM application and modelling tools, which they were not entirely ready to accept historical shapes database and their connected information. The first step was the Data Processing. It required the adaptation of a significant amount of data from 3D surveys. Accurate point clouds have been processed, cleaned and converted to proper management in BIM (Autodesk Revit) and pure modelling software (Mc Neel Rhinoceros). Data processing, thanks to the recent developments of Bentley Pointools and Autodesk Recap, has been able to extract, manage large scans and orient the exchange formats while maintaining the geometric peculiarities of complex elements such as vaults, pilasters, arches and decorations. The second phase (NURBS Generation) provided for the creation of complex Non-Uniform Basis Splines (NURBS) shapes from point clouds. Thanks to this methodology it has been possible to maintain the morphological complexities of each single architectural and structural element (from point clouds) without having to simplify the model and integrate any complex parts (vaults and walls) with highresolution orthophoto to favour the analytical interpretation of the structures, materials and the decay analysis. The extraction of geometric primitives based on NURBS algorithms such as polylines, splines, complex surfaces (32x32 UV) has improved the modelling, reducing time-consuming of the generative process of digital models in Autodesk Revit. 3D wireframe model and its correct export have favoured the develop of a parametric model in Autodesk Revit (as built H-BIM Generation - Volk, 2014) following the construction logic of the building and inserting each 3D element into its correspondent BIM family (third phase). The main advantage of this technique was the creation of smart $3 \mathrm{D}$ objects to which an almost limitless amount of information can be attached, expanding the intangible value of the built heritage. The creation of smart 3D objects, able to represent the real building details with high Level of Accuracy (LoA), has been the key to improving the management and aggregation of different types of information. Every single 3D object has been connected with information not only geometric (height, width, wall thickness, volume), but also stratigraphic information, materials, physical and technical properties and finally the historical phases. These grades of information have enabled the model to be managed in a time perspective (4D), showing the different historical phases of the building. The fourth phase, on the other hand, provided

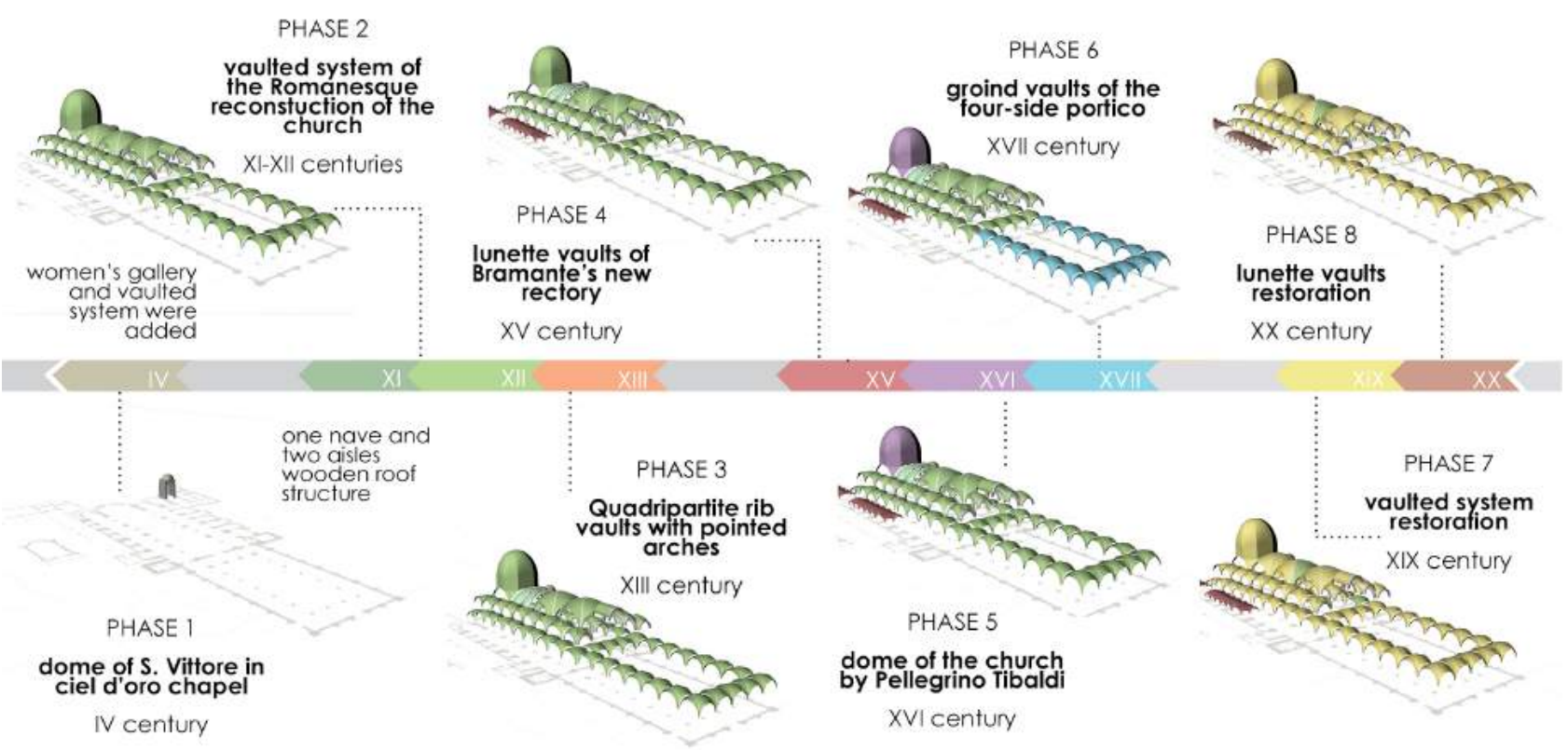

Figure 3. The vaulted system across the centuries 
for the conversion of the model for the latest generation devices such as Ipad, Phone via the 3D cloud. Autodesk A360 has been the software with which the model has been able to reach different types of users, favouring various aspects such as: displaying the most user-friendly three-dimensional model, visualisation and reading of model-related information, realtime sharing, automatic updating and finally increasing the dissemination of information at different levels.

\section{A CROSS-FEATURE IN THE BASILICA'S LIFE: THE VAULTED SYSTEM}

\subsection{Historical background}

Among the different transformations occurred across the overall architecture involving the plan, the elevation, the vertical enlargement and the covering systems of the church, the vaulted system is an example of the systematic modifications of the Basilica. That is why a focus on the changes of the covering system of the naves was carried out. The current arrangement is a gable roof with a concrete structure realized by Reggiori after the restoration. In some of the photos collected in Reggiori's report it was possible to see that the architect found the traces, on the back of the façade, of a previous gable roof which height is smaller than the current one. It is also possible to find this scheme, used in the first early Christian churches, in the drawings published by Landriani (Landriani, 1889). It is probably in the XI century that the vaulted system was realized (Reggiori, 1966; Arslan, 1953; Poter, 1917) and from that time on it deeply characterized the architectural arrangement of the church. It is possible to recognize different vault typologies, from the quadripartite rib vaults in the nave, and in the narthex to the groin vaults in the aisles, in the women's gallery, and in the four-sided portico. From the lunette vaults in the new rectory to the barrel vaults in the chapels of the north aisle. From the dome of the Presbytery, made of eight irregular masonry webbings, to the small domes of the chapels of the south aisle, and the mosaic dome of S. Vittore in ciel d'oro chapel (Rossi, 1884; Reggiori, 1941; Reggiori 1966; Brumana, 1990; Bella, 2013). These elements were built in different historical phases of the church and present distinct geometries, construction techniques and a proper restoration and transformation background that altered the possibility to read their peculiar characteristics and authenticity. The 3D model had a relevant role in understanding irregular geometry, construction anomalies, and construction techniques, and it was correlated with the historical data to explain specific aspects. This is an interesting example of how advanced modeling is used to optimize the dissemination of historical information and collected data, which are connected to the model itself.

\subsection{Recording Process}

The vaulted system was deeply rehashed and restored; the causes were always different and aimed at various purposes. The literature keeps traces of these changes and the major information was found thanks to focused bibliography research, like Carnet de voyage by De Dartein (Bella, 2013) that collects memories of the XIX century restoration, and the Chronicles of Mons. Rossi (Rossi, 1884). Thanks to these detailed reports, it was possible to identify, and focus on, specific aspects of the vaulted system that were modified during the XIX restoration. They were then correlated with the geometrical-dimensional data of the survey, and their comparison allowed understanding how the vaulted system was changed. During the generation of the 3D model, it was necessary to keep the complexity of the vaulted system, due to its many transformations and geometrical irregularities. Thermography was used to deepen the knowledge of the vaulted system and of the walls (where there are the vault springers), trying to see the masonry under the plaster layer. Thanks to this analysis, further observations came out, highlighting changes in the masonry of the rectory wall, like the transformation in the openings. This is correlated with the vaulted system of the Bramante's rectory and the south aisle of the church, and more generally with the changes occurred over the centuries. In fact, probably, the lunettes of the rectory were functional to a former arrangement of the rectory façade in which the openings were higher and with a curved top. During the XX century restoration, architect Reggiori changed the position and shape of the openings, which became smaller, rectangular and in the middle of each rectory span (Capponi,

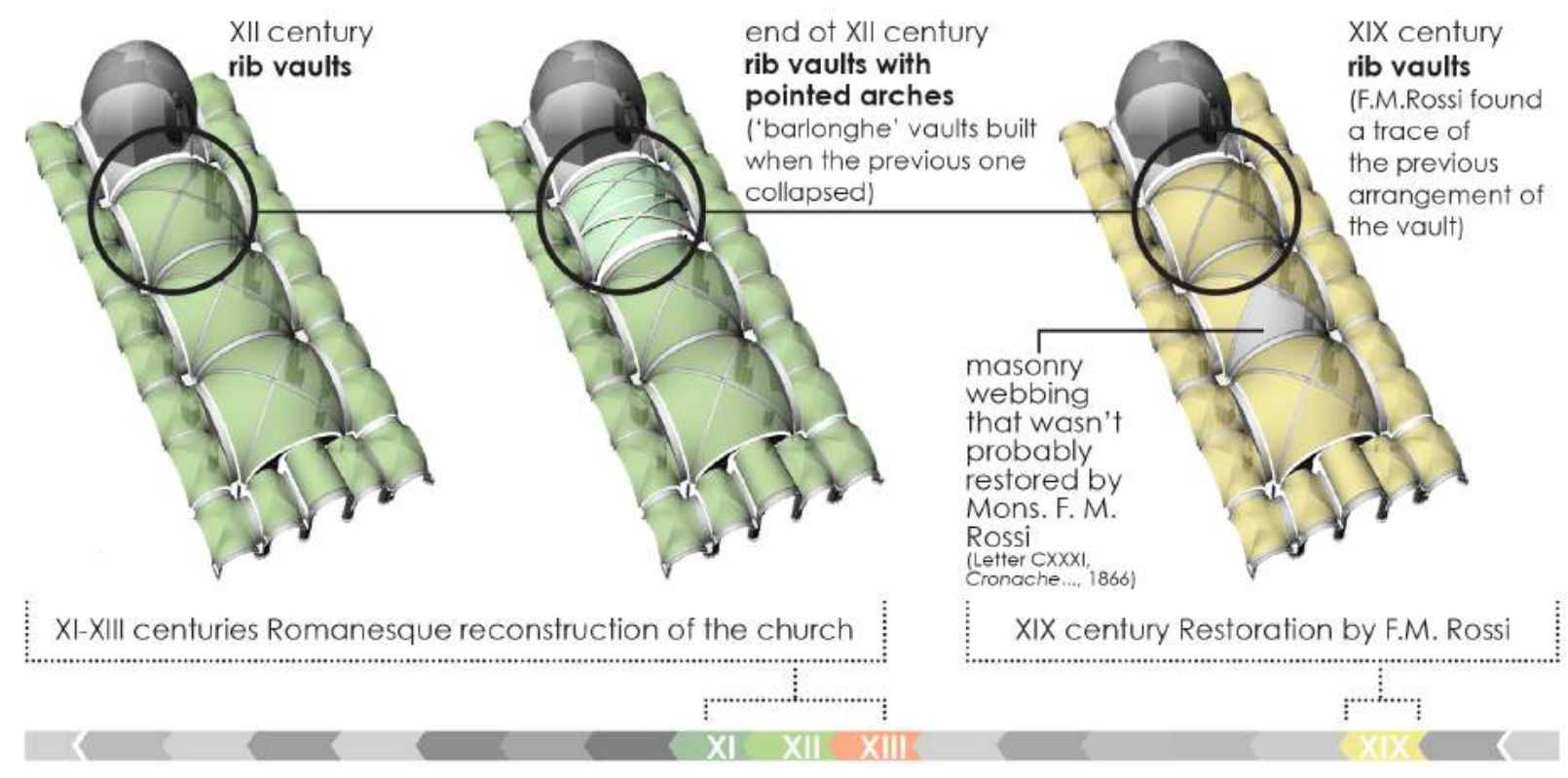

Figure 4. Changes occured at the nave's vaults 
1987). Furthermore, the thermal graphical images of the lunette showed a regular masonry that reflects the construction period these vaults collapsed during the Second World War and were rebuilt by Reggiori. During the on-site visits, several observations were collected through sketches and photos, which helped set the 3D model of the vaulted system. The 3D model was realized in Rhinoceros by importing the basic contours of each vault that were gained through the point cloud in AutoCAD. The contours necessary to obtain a 3D model of one part of the groin vaults were four: three for each contour and one to connect the two converging lines in order to define the proper profile and curvature of the vault. Once imported in Rhinoceros, the contours allowed the realization of the NURBS. The $3 \mathrm{D}$ model of the ribs of the groin vaults were realized through the creation of transversal sections in regular ranges, that were joined following the curved line of the rib. For the 3D model of the lunette vaults of the Bramante's rectory it was firstly realized the central barrel vault by joining the two end curved lines, secondly were realized the lunettes, using the same method of the groin vaults, and finally the barrel vault were intersected. The 3D models of the domes were realized depending on the morphology and geometry of each element. Basically, there were chosen concentric lines and/or ribs lines that were joined together.

\subsection{Analysis and interpretations}

The 3D model of the vaulted system proved to be a proper and efficient tool in providing a tridimensional and geometrical restitution of the construction complexity allowing adding also the past sequence of the different phases supporting a better comprehension by non-expert public. By reproducing with a 3D simulation the previous gable roof (which trace was found by Reggiori on the back of the façade) it was possible to state that this roof couldn't exist when the vaulted system was realized. It is part of an historical phase in which the church had another kind of roof structure. It is not possible to determine exactly the date when the covering system changed, but it is significant to the many transformations occurred, as it is for the vaulted system that changes its features in each period in the Basilica's life and it is an interesting theme for a transversal approach across the centuries. The vaulted system was set upon the timeline of the Basilica's life in order to have a picture of the main transformations: starting from the existing vaulted system - yellow, the main colour, is the one correlated to the XIX century restoration, while the brown is the one for the rectory's vaults, that were demolished by the bombings and restored in $\mathrm{XX}$ century - backwards in time until the foundation of the church in IV century, where only S. Vittore remains (Figure 3). One interesting hypothesis regards the transformation occurred at the vaulted system of the nave (Figure 4). Correlating the historical documentations (archive data and letters by mons. F. M. Rossi) with the drawings of the XVIII (Cassina, 1844) and XIX century (during the restoration works) it was possible to understand the changes of this part of the Basilica. Probably in the first phase of the rifabbrica romanica (Romanesque recontruction) the nave of the church was covered by rib groin vaults. Then, two rib vaults substituted the previous vault in the first span, probably after its fall, as some documents suggest. In fact, in the XII century the pulpit - that is located in the first span of the church - was seriously damage and arches in between the spans were built with other reinforced structures (Ambrosioni, 2003). This arrangement remains until the XIX century as Cassina documented in its publication (Cassina, 1844) and was removed by mons. F. M. Rossi because during the restoration he found the 'original' trace of the previous vault
Another thing that emerge from his letters is that the vaulted system was in a very bad state of conservation - that is why he restored it. There is just one webbing that seems not to be touched by his restoration: the east one of the second span of the nave. It will be really interesting to make further investigations of this vault in order to analyze its masonry texture and material.

\section{AN UNEXPLAINED FEATURE: BUTTRESSES AND ARC STRUCTURES OF THE NORTHEN SIDE OF THE BASILICA}

\subsection{Introduction}

Another part of the Basilica that was deeply analyzed is the arc structures that lean against the walls of the church and are observed at the level of the women's gallery. These are unique masonry elements made of five arches supported by pillars. The arches have irregular shapes and deformations - a complex geometrical double-curve wave (Figure 5) - whose cause remains unknown. During the Second World War the northern side of the Basilica was mainly damaged: bombs destroyed 9 spans of the 13 of the Bramante's rectory and one arc of the arc structures. The southern arc structure was partially demolished and modified due to the realization of the aisle chapels, which are all different in size and spatial shapes from the northern ones. Although it is now hard to fully analyze their geometry, structure, and stratigraphy, they were taken into account in order to make a comparison with the ones of the northern side of the Basilica. This arc structure is visible and easily accessible from S. Ambrogio room that is over the vaulted system of the Bramante's rectory. Bramante probably also designed the northern chapels, which perimetral wall doesn't lean against the pillars that supported the arches, and it is almost one meter away from them (Patetta, 1987). Other transversal arches connected the pillars and the perimetral wall to keep them more stable. This way, Bramante's project of the new rectory didn't change the northern arc structures. This study shows how even these structures went through different changes during the centuries depending on different ideas and purposes, as did the vaulted system or the windows. The research analyzed

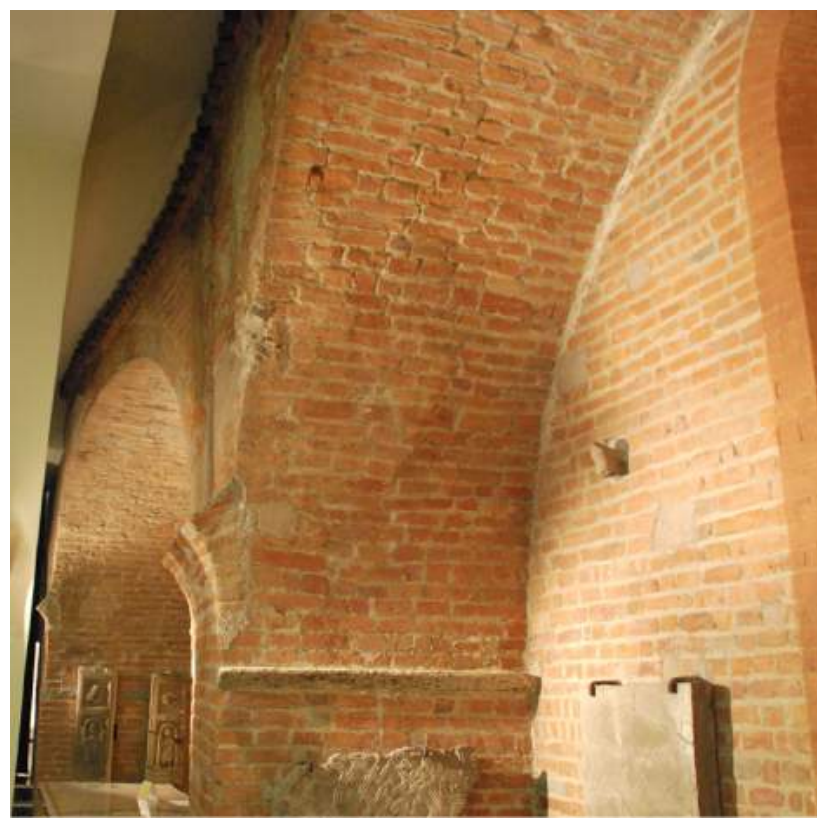

Figure 5. The double-curve wave 
thoroughly the XIX and XX centuries thanks to the rich documentation about the 'interpretive' restorations (Rossi, 1884; Landriani, 1889; Bella, 2013), and the restoration before and after the Second World World (Reggiori, 1966). This made it possible to correlate the 'signs' of the structures with the texts from the XIX-XX centuries. As for the other periods, the main source was the architecture itself - its materials, geometry, and construction techniques - because the documentation about this arc structures in the archives is scarce. Reggiori studied and analyze the structures and walls of this side of the Basilica after the aerial bombings revealed them - they were hidden by the Bramante's rectory. In the S. Ambrogio archive are stored several photos and drawings done by Reggiori during the restoration. Some of them are extremely curious, because they show hidden details, as the former horizontal section of the pillars that supported the arches, the former roof's traces, and the mural painting under the floor of S. Ambrogio room. Also, Reggiori investigated the creation of this arc structure - its origins and the reason for its construction - and he believed that first the pillars were built, then the arches in between them. In fact, it is still possible to see vertical signs between the pillars and the arches, and the two masonries are not interlocked.

\subsection{Modeling complexity: the study of the curious morphology of the arc structures}

The first step in the study of this arc structure was its representation through sketches and drawings based on hand measurement. Then laser scanning provided a more accurate survey that reproduced its complexity - in particular the doublecurve wave of each arc. However, some parts that remained hidden were surveyed by hand measurement as other details such as the window frame. Also, this structure presents so many irregularities and anomalies that an accurate direct observation is necessary. About 100 frontal photos were taken for each arc with a diffused and homogeneous light, using stairs in order to reach the upper parts. The 3D model of the surfaces was realized in PhotoScan and the orthophotos were exported and used for stratigraphic analysis, 2D drawings, and for mapping the 3D model itself (Figure 6). Thanks to the stratigraphic analysis (Figure 7), it was possible to highlight different

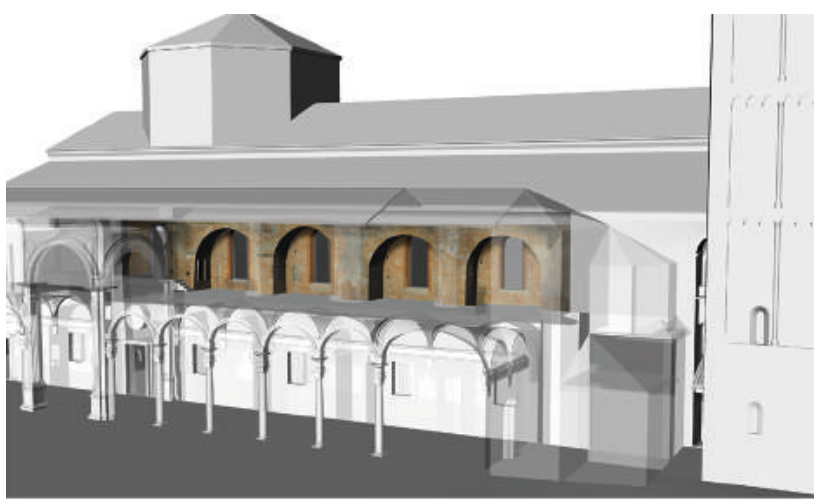

georeferenced photogrammetry

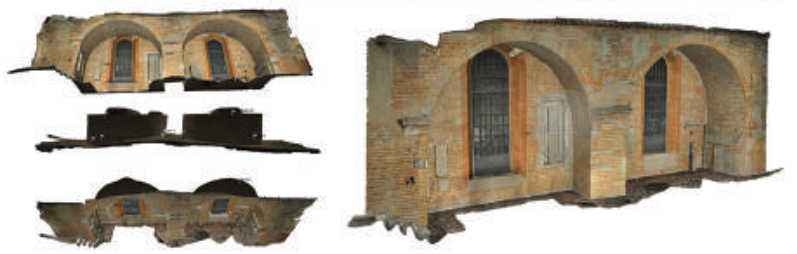

Figure 6. Photogrammetry workflow masonry textures, like the herringbone or mattonetti pattern, or brick finishing, such as the $45^{\circ}$ parallel, chevron, and oblique scratches (Fiorani, 2008). At the same time, this shed some light on the relationship between different masonry textures, realizing a chronology of the structure with the Harris matrix. The 3D model of the arc structure is the most detailed of this research its LOA reproduces as many geometrical-constructive irregularities and anomalies as possible. Its realization went hand in hand with the historical research, and this is correlated with the different LOD adopted for it. It has become gradually more accurate as the historical research proceeded in the study of the available documentation. It has been a fundamental role because all data were analyzed and combined till all facets have been investigated. Through the 3D model, the hypothesis was processed and verified in an easier way, and it was possible to define a theory on the evolution of this part of the Basilica, taking into account historical and geometrical data. The H-BIM was created with advanced NURBS modeling techniques. Also, the implementation of geometric primitives extraction from point clouds has allowed the generation of irregular surfaces of the church. The internal parts of the structure such as the clerestory, the aisles, the apse and the atrium were conducted through a cross-sectional study of the geometrical conditions of each element. Thanks to the NURBS interpolation algorithm has been possible obtain an automatic generation of the vaults from dense point clouds and the related 3D Wireframe. Extensive geometric test systems have yielded indication that NURBS generation of complex elements possesses userfriendly generative qualities. 3D Wireframe (mathematical boundaries), points (entities that make up the three-dimensional scans) with their spatial configurations (coordinates $\mathrm{x}, \mathrm{y}, \mathrm{z}$ in the digital space) represent the unique constraints of the generative methods. The masonry texture of the arc structure was obtained by attaching to the surfaces the orthophotos coming from the Photogrammetry projects. The final result has been calculated using as an internal formula of the NURBS application: the Deviation Value (DV) between point clouds, 3D objects and orthophotos was $2 \mathrm{~mm}$. This result has allowed a direct analysis in the digital space and a proper verification system (VS) of the LOA of the model. The high-resolution visualisations of the $\mathrm{H}-$ BIM and the related exchange formats have been fundamental
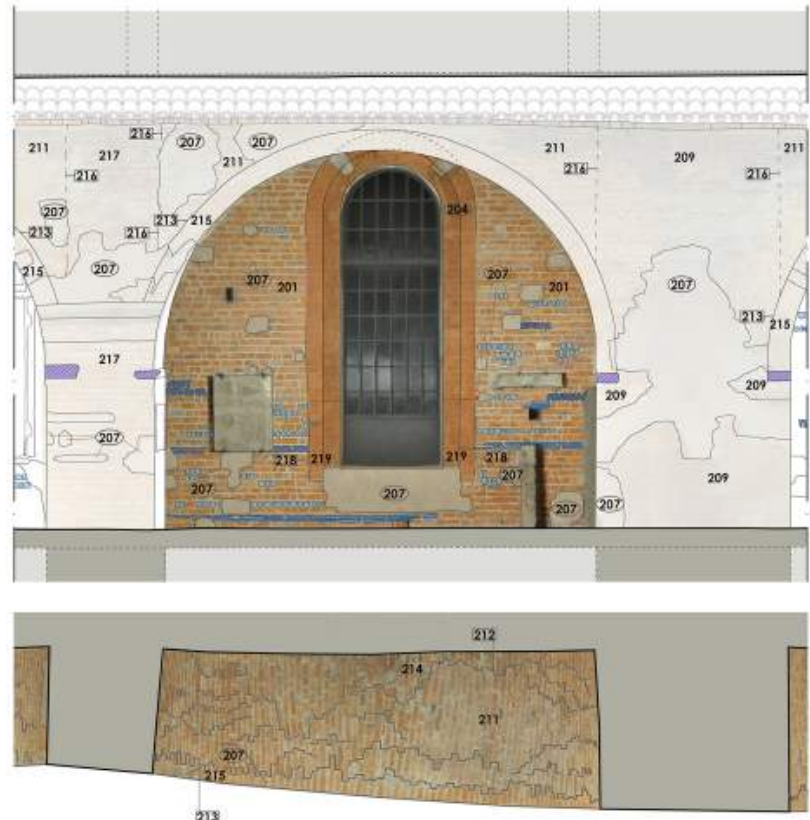

Figure 7. Example of stratigraphic analysis 
for both values (DV-VS). The qualitative and quantitative values have defined the LOA and LOI of the Basilica of S. Ambrogio BIM. Finally, the geometric primitives and the NURBS entities have allowed the definition of proper exchange formats for the transfer of the H-BIM in 3D apps of the latest generation. Autodesk A360 Team is based on a centralised project workspace that allows each user to mark up and comment the H-BIM and related documentation in the web browser or by the App directly, becoming a real N-D Virtual Notebook of the Basilica of S.Ambrogio. The automatic transfer of the model from BIM platform to phones/tablets had designed to ensure the dissemination of these historical treasures (reports, documents, historical phases, etc.) using various display modes for a different type of user (expert and not) and increasing the analytical approach of one of the most ancient Romanesque churches in the north of Italy. Thanks to the historical analysis, geometrical surveys and 3D modeling it was possible to formulate a hypothesis on the transformations occurred at arc structures. In detail, the double-curve wave can be the result of the connection of pillars with different shapes and dimensions. In the XII century the church presented square and polygonal pillars as De Dartein's drawings (Bella, 2013) and Reggiori's surveys shown (S. Ambrogio archive). Subsequently the polygonal pillars changed their horizontal sections into rectangular ones and then the arches were built in between the pillars - as the interruption visible on their masonries proves. The function of the structures was probably to reinforce the static behavior of the church. They weren't built in one phase and each element was progressively improved with supported devices and expedients. As mentioned above, the stratigraphic analysis shows that first the pillars were built, then the arches in between them. It is not possible to certainty state the reason of their construction and during the research three hypotheses were taken into consideration. The first one is the necessity to reinforce the church structures after the fall of the vault of the first span of the Basilica (Porter, 1917; Ambrosioni, 2003). The second one is connected with the nave vaults: matronei and arc structures have to contrast the load of the nave's vaults (Reggiori, 1966). The third one is related to the devastating earthquake occurred in Milan in 1117 - the arc structures could have been realized in order to counter the seismic loads. The reason of their construction remains uncertain and can be deepened with future researches. It will be really interesting to integrate the two side with the arc structures of the Basilica into the traditional Basilica's tour in order to show not only the historical and 'hidden' changes of the church but also the strictly relationship between the different elements that characterized it - e.g. Bramante's portico and the aisles of the church.

\section{CONCLUSION}

This essay offers an integrated approach to the study of historic buildings, taking the idea of a subtraction process from archaeology, clearly a virtual one.

Through the archaeological approach, this architecture research on the S. Ambrogio Basilica allowed to see the church as a whole product, but also as a palimpsest to read and observe in all its facets. Because of this, the resulting virtual notebook has a complex structure, made of observations and elements, whose reasons are sometimes easily explainable and sometimes still unknown (Figure 8).

The 3D model of the church has two main functionalities: on the one hand, it was a useful resource during this study; on the other, it makes the collected data easily accessible and understandable even to non-experts, thus creating a virtual notebook, ideally usable by anyone at any given time, for example tourists, students, and researchers. One possible implementation of this notebook is the creation of a mobile app that provides useful information on different elements of the church while visiting it. Thanks to the methodological approach and the 3D simulations was possible to study the church from a different point of view, correlating geometrical data with historical ones, break up and put back together the historical phases, hypotheses, construction elements, following a virtual subtraction process that made it possible to study the Basilica in all its aspects with different Level of Details. This shows the great complexity of the church and wants to rise the awareness of the importance of all the historical phases that has to be understand during the on site visit of the Basilica by tourists and experts. This essay can be considered as a starting point for the creation of the virtual notebook, through which the virtual reality supports the knowledge acquired from the study.

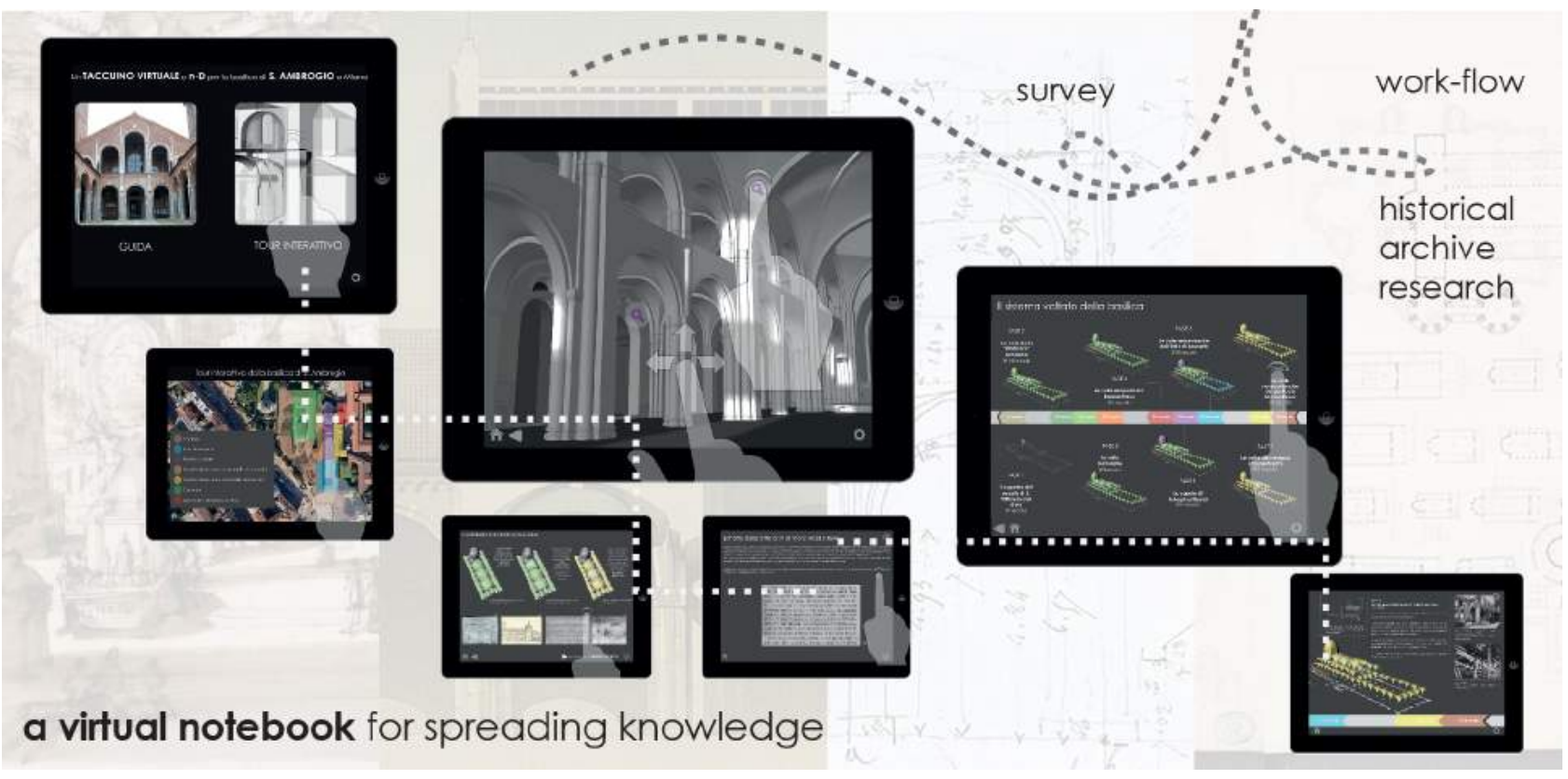

Figure 8. Interfaces of the virtual notebook of the Basilica 
Further time and resources have to be invested in order to fully represent the complexity and the contradictions highlighted in the integrated analysis.

\section{REFERENCES}

Ambrosioni A., 2003. Milano, papato e impero in età medievale. Raccolta di studi. V\&P università, Milano.

Arslan E., 1953. L'architettura romanica Milanese. In: AAVV, Storia di Milano, Fondazione Treccani degli Alfieri per la storia di Milano.

Banfi F. 2016, Building Information Modelling - A Novel Parametric Modeling Approach Based on 3D Surveys of Historic Architecture. In: Ioannides M. et al. (eds) Digital Heritage. Progress in Cultural Heritage: Documentation, Preservation, and Protection, EuroMed 2016, Lecture Notes in Computer Science, vol 10058. Springer, Cham.

Barazzetti L., Banfi F., 2017. Historic BIM for mobile VR/AR applications. In: Mixed Reality and Gamification for Cultural Heritage, Chapter 9, Editors: Marinos Ioannides, Nadia Magnenat-Thalmann, George Papagiannakis, Springer International Publishing.

Barazzetti, L., Banfi, F., Brumana, R., Gusmeroli, G., Previtali, M., Schiantarelli, G., Cloud-to-BIM-to-FEM: Structural simulation with accurate historic BIM from laser scans. In: Simulation Modelling Practice and Theory, pp. 71-87.

Barazzetti, L., Banfi, F., Brumana, R., Lostaffa, F., Piraino, F., Previtali, M., Oreni, D., Roncoroni, F., Villa, L., 2015. BHIMM e Augmented Information: il rilievo per la conoscenza e la valorizzazione di Castel Masegra, 2015, ASITA, pp. 35-45.

Barazzetti, L., Banfi, F., Brumana, R., Previtali, 2015. Creation of parametric BIM objects from point clouds using NURBS. In: Photogram Record, 30, pp. 339-362.

Bella T., 2013. La basilica di Sant'Ambrogio a Milano. L'opera inedita di Fernand de Dartein, Jaka Book, Milano.

Boato A., 2008. L'archeologia in architettura, Marsilio Editore, Venezia.

Brumana R., 1990. Sant'Ambrogio's Basilica in Milan. A study on photogrammetric surveys in the S. Vittore in Ciel d'Oro's dome. In: Close-Range Photogrammetry Meets Machine Vision (Proceedings of SPIE- The International Society for Optical Engineering), vol. 1395, dicembre 1990.

Campioli A., 2005. Volte da manuale. Costruire in Laterizio, $\mathrm{n}$. 107 - Strutture voltate, sett-ott.

Capponi C., 1987. I restauri ottocenteschi al portico della Canonica di S. Ambrogio. In: Bramante a Milano: congresso internazionale promosso dall'Università Cattolica del Sacro Cuore, Dipartimento di studi medioevali, umanistici e rinascimentali, Milano, 3-7, giugno 1986, vol. II, Il Vaglio Cultura Arte,Milano, p.71.

Cassina F., 1844. Le fabbriche più cospicue di Milano, Milano Chiavoni E., Filippa M., 2007. Metodologie integrate per il rilevo, il disegno, la modellazione dell'architettura e della città, Gangemi Editore, Roma.
Fai, S., Graham, K., Duckworth N Wood, T., Attar, R., 2011. Building information modelling and heritage documentation. 23rd International Symposium, International Scientific Committee for Documentation of Cultural Heritage (CIPA). Prague, Czech Republic.

Fiengo G., Bellini A., Della Torre S., 1994. La parabola del restauro stilistico nella rilettura di sette casi emblematici, Guerini studio

Fiorani D., 2008. Finiture murarie e architetture nel medioevo. Una panoramica di tre casi di studio nell'Italia centromeridionale, Gangemi Editore, Roma.

Gatti Perer M. L., 1995. La basilica di S. Ambrogio: il tempio ininterrotto, vol. 1-2, Vita e pensiero, Milano.

Landriani G., 1889. La Basilica Ambrosiana fino alla sua trasformazione in chiesa lombarda a volte, Hoepli, Milano.

Lusuardi Siena S., 1997. Ambrogio, il costruttore sapiente. In: Rizzi M., Pasini C., Rossignani M.P., La città e la sua memoria: Milano e la tradizione di Sant'Ambrogio, Electa, Milano.

Oreni, D., Brumana, R., Cuca, B., 2012. Towards a Methodology for 3D Content Models. The Reconstruction of Ancient Vaults for Mainenance and Structural Behaviour in the Logic of Bim Management. Virtual System in the Information Society. NJ, USA, Milan-Italy, pp. 475-482.

Oreni, D., Brumana, R., Della Torre S., Banfi, F., Barazzetti, L., Previtali, M., 2014. Survey turned into HBIM: the restoration and the work involved concerning the basilica di Collemaggio after the earthquake (1'Aquila). In: ISPRS Annals of the Photogrammetry, Remote Sensing and Spatial Information Sciences, Vol. II-5, 2014, Riva del Garda, Italy, pp. 267-273.

Patetta L., 1987. L'architettura del Quattrocento a Milano, Clup, Milano.

Piegl L., Tiller W., 1997. The NURBS Book, Monographs in Visual Communication, second ed., Springer-Verlag New York, Inc., New York, NY.

Porter A. K., 1917. Lombard Architecture, vol. 2, New Haven: Yale University press, London.

Reggiori F., 1941. La basilica ambrosiana: ricerche e restauri 1929-1940, Hoepli, Milano.

Reggiori F., 1966. La basilica di Sant'Ambrogio, Cassa di Risparmio, Milano.

Rossi F. M., 1884. Cronaca dei ristauri e delle scoperte fatte nell'insigne basilica di S. Ambrogio dall'anno 1857 al 1876 , Tipografia S. Giuseppe, Milano.

Sannazzaro M., 2009. "Cottidie pergebam ad martyres". I dintorni della basilica di S. Ambrogio nel IV secolo: tradizione letteraria e documentazione archeologica. In: AAVV, Studia ambrosiana, vol. 3: Ambrogio e la sua basilica, Bulzoni Editore, Città di Castello.

Volk, R., Stengel, J., Schultmann, F., 2014, Building Information Modeling (BIM) for existing buildings - Literature review and future needs. Automation in Construction, 38. 